\title{
AN EVALUATION OF SOLUTIONS TO MOMENT METHOD OF BIOCHEMICAL OXYGEN DEMAND KINETICS
}

\author{
I. A. Oke ${ }^{1, *}$, S. Lukman' ${ }^{2}$, J. S. Amoko ${ }^{3}$ and E. O. Fehintola ${ }^{4}$ \\ 1, DEPARTMENT OF Civil ENGINEERING, OBAFEMI AWOLOWo UNIVERSITY, ILE-IFE, OSUN STATE, NIGERIA \\ 2, Dept. of Water Resources \& Environmental Engineering, Ahmadu Bello Univ., Zaria, Kaduna State. NiGERIA \\ 3,4 DEPARTMENT OF CHEMISTRY, AdEYEMI FEDERAL Univ. of EDUCATION, ONDO, ONDO STATE. NIGERIA \\ E-mail addresses.1 okeja@oauife.edu.ng, 2 salihulukman@yahoo.com, \\ 3temiamoko@gmail.com, ${ }^{4}$ sfeintola@yahoo.com
}

\begin{abstract}
This paper evaluated selected solutions of moment method in respect to Biochemical Oxygen Demand (BOD) kinetics with the aim of ascertain error free solution. Domestic-institutional wastewaters were collected two-weekly for three months from waste-stabilization ponds in Obafemi Awolowo University, Ile-Ife. BOD concentrations (BOD $)_{c}$ were determined daily for 8 days using standard method. The $B O D_{c}$ were used to determine parameters in BOD kinetics (ultimate BOD concentration and BOD removal rate) using Microsoft Excel Solver, non-linear regression (exponential) and least squares methods (three graphs). Accuracies of these solutions were evaluated using relative error, Akaike Information Criterion (AIC), and model of selection criterion (MSC). The study revealed that ultimate $B O D_{c}$ was in the range of 1368.7 to $860.6 \mathrm{mg} / \mathrm{L}$ and $B O D_{c}$ removal rate was between -0.139 and $-0.470 / d$. The averages of MSC were 4.18; 0.01; 1.49, 1.28 and 1.61 for Microsoft Excel Solver, non-linear and three least square methods (graphs 1, 2 and 3) respectively. The result revealed that Microsoft Excel Solver provided an improved solution of moment method, and a good description of $B O D_{c}$ removal trend based on MSC and AIC than the other solutions. The study concluded that Microsoft Excel Solver solution to the method is a valuable solution at higher confidence level based on lower values of AIC and high values of MSC.
\end{abstract}

Keywords: Wastewater, Environmental Pollution Control, BOD Kinetic Parameters, Moment Method, Statistical Evaluation

\section{INTRODUCTION}

Biological treatment methods of wastewaters treatment are in use for wastewaters from textile, tannery, pulp and paper mill, pharmaceutical and paint industries [1- 5]. These wastewater treatment processes are found useful because of their operational and initial costs are significantly lower than any other wastewater treatment process $[6 ; 7]$. $\mathrm{BOD}_{\mathrm{c}}$ and BOD kinetics are the most widely used parameters for organic pollution control and the determination of strength of wastewaters. $\mathrm{BOD}_{\mathrm{c}}$ is a measure of the dissolved oxygen used by microorganisms in the biochemical oxidation of organic matters. $\mathrm{BOD}_{\mathrm{c}}$ can be in the form of Carbonaceous Biochemical Oxygen Demand (CBOD) or Nitrogenous Biochemical Oxygen Demand (NBOD, Figure 1). They are the amount of oxygen required to oxidize carbonaceous (organic carbon, carbohydrates) or nitrogenous (organic nitrogen, nitrate, nitrite, ammonia, etc.) compounds respectively by microorganisms at specified day and temperature. These two types $\mathrm{BOD}_{\mathrm{c}}$ are expressed as follows: Amount of oxygen required to oxidise nitrite to nitrate can be expressed as equation (1):

$$
U O D N_{I}=1.14 \times \mathrm{NO}_{2}-\mathrm{N}
$$

In (1), $\mathrm{NO}_{2}-\mathrm{N}$ is the Nitrite - nitrogen concentration $(\mathrm{mg} / \mathrm{l})$ and $\mathrm{UODN}_{\mathrm{i}}$ is the Ultimate oxygen demand for nitrite oxidation ( $\mathrm{mg} / \mathrm{l})$. The amount of oxygen concentration required to transform (oxidize) ammonia to nitrate is estimated as:

$$
U O D N_{i a}=4.57 \times A m m-N
$$

In (2), $\mathrm{UODN}_{\mathrm{ia}}$ is the ultimate oxygen demand for ammonia- nitrogen oxidation (mg/l) and Amm-N is the ammonia - nitrogen concentration (mg/l) 
The amount of oxygen concentration required to remove (oxidize) organic nitrogen can be computed as:

$$
U O D N=4.57 \times O N A
$$

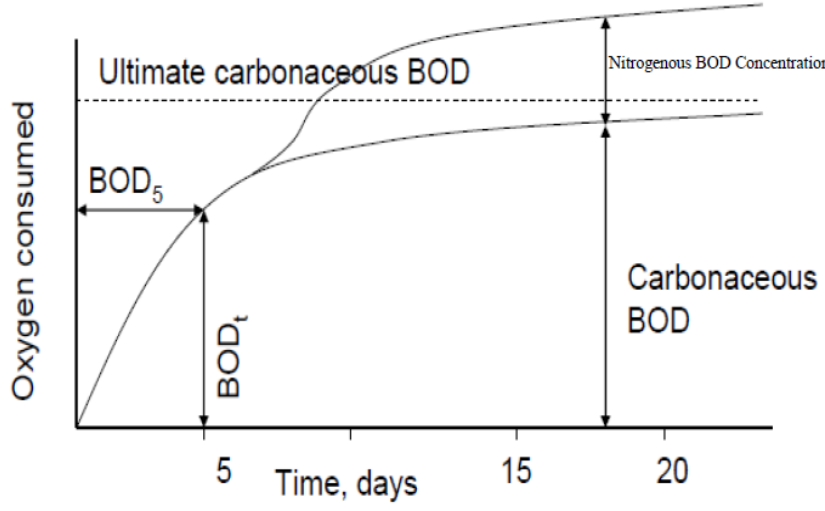

Figure 1: Patter of First order kinetics of Carbonaceous and Nitorgenous BOD concentrations [5]

In (3), is the ultimate oxygen demand for organic nitrogen oxidation $(\mathrm{mg} / \mathrm{l})$ and $\mathrm{ON}$ is the organic nitrogen concentration (mg/l). Carbohydrates are transformed (oxidized) under anaerobic conditions to yield carbon (IV) oxide and methane as:

$$
\begin{aligned}
C_{n} H_{a} O_{b}+\left(n-\frac{a}{4}\right. & \left.-\frac{b}{2}\right) \mathrm{H}_{2} \mathrm{O} \\
& \rightarrow\left(\frac{n}{2}-\frac{a}{8}-\frac{b}{4}\right) \mathrm{CO}_{2} \\
& +\left(\frac{n}{2}-\frac{a}{8}-\frac{b}{4}\right) \mathrm{CH}_{4}
\end{aligned}
$$

Anerobic:

$$
\begin{aligned}
C_{n} \mathrm{H}_{a} \mathrm{O}_{b}+\left(\frac{n}{2}-\frac{a}{2}\right. & \left.-\frac{b}{2}\right) \mathrm{O}_{2} \\
& \rightarrow\left(n-\frac{a}{4}-\frac{b}{2}\right) \mathrm{CO}_{2}+\left(\frac{a}{4}+\frac{b}{2}\right) \mathrm{H}_{2} \mathrm{O} \\
& + \text { Energy }
\end{aligned}
$$

Schroeder [8] suggests the use of equation (4) to estimate the rate of methane production as:

$$
M_{C H}=0.35\left(\eta Q C_{B O D i}-1.42 R_{g} V\right)
$$

In (5) $\eta$ is the constant as multiplication factor; $C_{B O D}$ is the influent $\mathrm{BOD}_{\mathrm{c}}(\mathrm{mg} / \mathrm{l}), \mathrm{M}_{\mathrm{CH}}$ is the methane produced per day $\left(\mathrm{m}^{3} / \mathrm{d}\right), \mathrm{Q}$ is the discharge or flow rate $\left(\mathrm{m}^{3} / \mathrm{d}\right)$, $\mathrm{R}_{\mathrm{g}}$ is the rate of bacterial growth $(/ \mathrm{d})$ and $\mathrm{V}$ is the volume of the liquid $\left(\mathrm{m}^{3}\right)$. Similarly, Tebbutt [9] reports that carbohydrates are oxidized under aerobic conditions to yield carbon (IV) oxide and water (Equation 6).

$$
\mathrm{C}_{n}\left[\mathrm{H}_{2} \mathrm{O}\right]_{y}+(n) \mathrm{O}_{2} \rightarrow(n) \mathrm{CO}_{2}+(y) \mathrm{H}_{2} \mathrm{O}
$$

The amount of oxygen concentration required by microorganisms to oxidise carbohydrate in wastewater to water and carbon-(IV) oxide can be computed:

$$
U O D_{L}=2.67 \times O C
$$

In (7), OC is the organic carbon or volatile solids concentration $(\mathrm{mg} / \mathrm{l})$ and $\mathrm{UOD}_{\mathrm{L}}$ is the ultimate oxygen demand for carbohydrate oxidation (mg/l). In environmental pollution control, BOD kinetic parameters are in use to:

a) Estimate the quantity of oxygen concentration that will be required to stabilize organic matter present in wastewater using biological processes;

b) ascertain the critical point and the critical oxygen concentration deficit in oxygen sag curve, which is applicable in the self-purification of water bodies $[9,10,11]$;

c) estimate the size of waste-treatment plant required through the use of surface BOD loading $[6,12,13,14]$;

d) design major biological treatment plants (ponds, lagoons, trickling bed filter, etc.); and

e) evaluate performance of some biological treatment processes [12].

The key design parameters in BOD kinetics are ultimate $\mathrm{BOD}_{\mathrm{c}}\left(\mathrm{L}_{\mathrm{o}}\right)$ and rate of $\mathrm{BOD}_{\mathrm{c}}$ removal $(\mathrm{k})$. There are various kinetics models for BOD kinetics in the literature [15-37]. The first order kinetics model of $\mathrm{BOD}_{\mathrm{c}}$ has been the widely used. Equation (8) presents first order BOD kinetics model and the kinetic parameters.

$$
Y_{T}=L_{o}\left(1-\exp ^{k t}\right)=L_{o}\left(1-10^{k^{\prime} t}\right)
$$

Here: $\mathrm{L}_{0}$ is the ultimate $\mathrm{BOD}_{\mathrm{c}}(\mathrm{mg} / \mathrm{l}), \mathrm{EXP}$. is the exponential, $\mathrm{k}^{\prime}$ is the rate of $\mathrm{BOD}_{\mathrm{c}}$ removal $(/ \mathrm{d})$ in base $10, \mathrm{k}$ is the $\mathrm{BOD}_{\mathrm{c}}$ removal rate at base e $(/ \mathrm{d})$ and $\mathrm{t}$ is the time of incubation (d)

There are several methods of solution for the determination of these two essential design parameters ( $\mathrm{k}$ and $\mathrm{L}_{\mathrm{o}}$ ) from a series of $\mathrm{BOD}_{\mathrm{c}}$ measured. The methods and solution include non-linear regression (graphical), least square, Lee's and Moment [25], the logarithms difference, daily difference, rapid-ratio, Fujimoto and the Thomas methods [5]. Some of the methods have been used, but utilization and solution of the Moment method for BOD kinetics are rare in literature [28 - 35].

The method was developed by previous researchers [25]. The method involves fitting the BOD concentration to a first order kinetics curve that has its first two moments equivalent to the moment of those of the experimental $\mathrm{BOD}_{\mathrm{c}}$. The values of $\mathrm{L}_{\mathrm{o}}$ and $\mathrm{k}$ in the BOD kinetics are determined from equations (9 and 10) $[5,7,37]$ :

$$
\sum_{i=1}^{n} y_{i}=n L_{o}-L_{o} \sum_{i=1}^{n} \exp ^{-(k t,)}
$$




$$
\sum_{i=1}^{n} y_{i} t_{i}=L_{o} \sum_{i=1}^{n} t_{i}-L_{o} \sum_{i=1}^{n} t_{i} \exp ^{-(k t,)}
$$

From equations (9 and 10) the values of $\frac{n-\sum_{i=1}^{n} \exp ^{-(k t,)}}{\left.\sum_{i=1}^{n} t_{i}-\sum_{i=1}^{n} t_{i} \exp ^{-(k t)}\right)}$ are obtained from $\frac{\sum_{i=1}^{n} y_{i}}{\sum_{i=1}^{n} y_{i} t_{i}}$ and the value of $\mathrm{k}$ can be determined from the two expressions. The value of $L_{0}$ can be obtained using Equation (9) or Equation (10). Non-linear regression and least squares methods are computer and graphical based methods which can be used to determine these parameters $[5,7$ 37]. All these solutions and methods have some limitations in utilizations, performance accuracy, reliability and validity in BOD kinetics. These limitations arise because the solutions and methods were eithier consequent of either a numerical and mathematical equation or fitting curves into a linear equation. Literature [5] described that all these numerical and mathematical approaches as unjustifiable mathematically and statistically. Some researchers $[5,38]$ evaluated of some of these BOD kinetics methods without any consideration to moment method. Thus the need for statistical evaluation of moment method in estimation of BOD kinetics is required. The focal objective of this study is to use Microsoft Excel Solver, non-linear regression and least squares in the determination first order $\mathrm{BOD}_{\mathrm{c}}$ kinetics parameters in moment method and to present their statistical evaluations.

\section{MATERIALS AND METHOD}

Wastewater samples were composed from an influent into domestic -institutional waste stabilization ponds of Obafemi Awolowo University, Ile-Ife, Nigeria every two weeks for three months (between January and March, 2013) at different days. The BOD of the samples were determined daily for the first eight days using respirometric method specified in APHA [39]. The procedures for BOD dtermination were repeated for blanks. The $\mathrm{BOD}_{\mathrm{c}}$ were read directly from the graduated tubes on the equipment and the readings were multiplied by dilution factor to obtain actual $\mathrm{BOD}_{\mathrm{c}}$ (mg/l). Calculations of the BOD kinetics parameters (ultimate BOD and rate of BOD concentration removal) were conducted using Microsoft Excel Solver, nonlinear regression (Exponential) and the least squares (three graphical methods) methods. Statistical evaluations of the performance of the calculations were conducted using Analysis of Variance (ANOVA), errors [5], Akaike Information Criterion (AIC) and MSC. The model of selection criterion (MSC) interprets the proportion of expected BOD concentrations (experimental BOD concentrations) variation that can be explained by the calculated BOD concentrations (BOD concentrations from the methods). A higher value of MSC indicates higher accuracy, validity and the goodness of fit of the methods. MSC was computed using Equation (11) as follows:

$$
M S C=\operatorname{In}\left(\frac{\sum_{i=1}^{n}\left(Y_{\text {expcti }}-\bar{Y}_{\text {expect }}\right)^{2}}{\sum_{i=1}^{n}\left(Y_{\text {expcti }}-\bar{Y}_{\text {cali }}\right)^{2}}\right)-\frac{2 P}{n}
$$

In (11), $Y_{\text {expect }}$ is the BOD concentrations from the experimental study; $\overline{\mathrm{Y}}_{\text {expect }}$ is the average BOD concentrations from the experimental study; $p$ is the total number of fixed parameters to be estimated in the methods; $\mathrm{n}$ is the total number of BOD concentrations calculated, and $Y_{\text {cali }}$ is the BOD concentration calculated using any of the selected methods.

Akaike Information Criterion: Information Criterion of Akaike [40] allows a direct comparison of different methods with a different number of parameters [5]. It represents the information content of a given set of parameters by linking the coefficient of determination to the number of parameters (or equivalently, the number of degrees of freedom) that were required to establish the fit. The Akaike Information Criterion (AIC) was determined using the expression (Equation 12):

$$
A I C=N\left(\operatorname{In} \sum_{i=1}^{n}\left(Y_{\text {expcti }}-Y_{\text {cali }}\right)^{2}\right)+2 p
$$

Where; $\mathrm{p}$ is the total number of fixed parameters to be computed in the methods; $\mathrm{N}$ is the total number of BOD concentration computed. Sum of Square (SS), Mean Square (MS) and F-Value were computed as follows (Equations 13 - 15) [5]:

$$
S S A=\left(E_{H A S}\right)^{2} r\left(2^{k-2}\right)
$$

In (13), SSA is the sum of the squares of factor $A ; r$ is the replication of the $\mathrm{BOD}$ concentration $(=1), \mathrm{E}_{\mathrm{HAs}}$ is the effect of factor $A$ and $\mathrm{k}$ is the level of the factor.

$$
M S A=\frac{S S A}{N-1}
$$

Here, MSA is the mean square of the factor and N-1 is the degree of freedom of the factor.

$$
F=\frac{M S A}{M S E}
$$

In (15) MSE is the mean square of the error in respect of the factor and $F$ is the $F$-value of the factor. Computations of ultimate $\mathrm{BOD}_{\mathrm{c}}$ and $\mathrm{BOD}_{\mathrm{c}}$ removal rate were computed using Microsoft Excel Solver as follows:
a) Microsoft Excel Solver was added in;
b) Target value was set using chi square as: 


$$
\left[\sum_{t=1}^{n} B O D_{t}-L_{o}\left(1-e^{-k t}\right)\right]^{2}=0
$$

c) Changing cells were selected $\left(\mathrm{L}_{o}\right.$ and $\left.\mathrm{k}_{1}\right)$,

d) Number of iterations, degree of accuracy and maximum time were set; and

e) The target was Solved using solver (Figure 2 presents the flow chart of the procedures).

For least squares calculations the ratio of $\frac{\sum_{i=1}^{n} y_{i}}{\sum_{i=1}^{n} t_{i} y_{i}}$ was used for the value of $\mathrm{k}_{1}$ and $\mathrm{L}_{o}$ determination.

For non-linear calculations three different graphs were employed as follows:

a) For exponential (graph 1) calculations, $\mathrm{BOD}_{\mathrm{c}}$ were plotted against the incubation times and the values of $\mathrm{k}$ and $\mathrm{L}_{\mathrm{o}}$ were determined;

b) For graph 2, daily rate change in $\mathrm{BOD}_{\mathrm{c}}\left(\mathrm{BOD}_{\mathrm{t}+1}-\right.$ $\mathrm{BOD}_{\mathrm{t}}$ ) were plotted against the incubation times (Exponential) and the values of $\mathrm{k}$ and $\mathrm{L}_{\mathrm{o}}$ were determined; and

c) For graph 3 , rate change in $\mathrm{BOD}_{\mathrm{c}}\left(\frac{\partial \mathrm{BOD}_{\mathrm{t}}}{\partial t}\right)$ were plotted against the incubation times (linear) and the values of $\mathrm{k}$ and $\mathrm{L}_{\mathrm{o}}$ were determined.

\section{RESULTS AND DISCUSSION}

The first 5-days biochemical oxygen demand concentration curves for the wastewaters were as presented in Figure 3. Figure 4 presents BOD remaining curves of the first 10- days for influent wastewaters based on first kinetic order. The curves show a common lag time of less than a day. The curves revealed that the minimum BOD concentration was $400 \mathrm{mg} / \mathrm{l}$ and the maximum was $1350 \mathrm{mg} / \mathrm{l}$. These BOD concentrations indicate the wastewaters were strong wastewater [41]. A statistical evaluation of the BOD concentration (Table 1) revealed that there was a significant difference between the samples $\left(F_{5,20}=19.26308 ; \mathrm{p}=4.97 \times 10^{-}\right.$ $\left.{ }^{07}\right)$ and the BOD concentration consumed $\left(\mathrm{F}_{4,205}=\right.$ 439.5549; $\left.\mathrm{p}=3.53 \times 10^{-19}\right)$ at $99 \%$ confidence level. From these figures, the BOD curves show a slight distinctive, three-phase profile, comprising an initial period of rapid oxygen uptake, a shoulder-like transition phase and then an extended period of slower oxygen uptake activity. This pattern was observed throughout the study period for all the BOD curves. The patterns of BOD concentration are the existence of similar patterns for carbonaceous BOD concentration (Figure 5). Individual BOD concentration and incubation time demonstrated a low degree of scattering or low noise, which could be attributed to the accuracy of the method [39] and the instrument. The three- phase profile indicates that there was a decrease in the rate of BOD concentration removal and the wastewaters were not homogenous in nature, rather, the wastewaters were heterogenous in nature [41].

The ultimate $\mathrm{BOD}_{\mathrm{c}}$ from the $\mathrm{BOD}_{\mathrm{c}}$ analysis using these selected methods were as presented in Table 2. The ultimate BOD ranges from $1368.7 \mathrm{mg} / \mathrm{l}$ to $3806.6 \mathrm{mg} / \mathrm{l}$. These values were similar to the ultimate BOD concentration documented in the literature for domestic wastewater. These wastewaters can be classified as strong domestic wastewaters [5, 10, 41]. A statistical analysis (Table 3) of the ultimate BOD shows that there was a significant difference between the methods $\left(F_{4,20}=451.4 ; p=0.00000\right)$ at $99 \%$ confidence level $(p<0.01)$. An evaluation of ultimate BOD concentration revealed that there was a difference between the ultimate BOD concentrations. This difference shows that the wastewaters were heterogeneous in composition. The differences were significant $\left(F_{5}, 20=11.5 ; p=0.00002\right)$ at $99 \%$ confidence level $(\mathrm{p}<0.01)$. This result indicates that there was a significant difference between the methods at 99 percent confidence level and that ultimate BOD is a function of the method used.

The values of the $\mathrm{BOD}_{\mathrm{c}}$ removal rate (kinetic coefficients) for each assay determined by the five different methods were as presented in Table 4. It can be seen that there are differences among the values of the constants calculated by the different methods. The kinetic coefficients range from $-0.139 / \mathrm{d}$ to $-0.470 / \mathrm{d}$. These values were similar to the kinetic coefficients documented in the literature for untreated domestic wastewater [41]. These wastewaters can be classified as strong domestic wastewaters $[10,41]$. A statistical analysis (Table 5) of the kinetic coefficients shows that there was a significant difference between the methods $\left(\mathrm{F}_{4,20}=100.1183 ; \mathrm{p}=0.00000\right)$ at $99 \%$ confidence level ( $p<0.01)$. An evaluation of kinetic coefficients revealed that there was a difference between the kinetic coefficients. The differences were not significant $\left(F_{5,20}=1.417905 ; p=0.2606\right)$ at $90 \%$ confidence level $(\mathrm{p}>0.1)$. This result indicates that there was a significant difference between the methods at $99 \%$ confidence level and that kinetic coefficients are functions of the method used.

The values of the ultimate BOD concentration and kinetic coefficients for each assay determined by the different methods presented (Tables 2 and 4) revealed that there were differences in the values of the ultimate BOD concentration and kinetic coefficients calculated by the different methods. However, a comparison by inspection does not give room to draw conclusions. Errors (relative and total), MSC and AIC were used to 
assess the goodness of fit for each method (Tables 6 to 9). The relative error and the AIC are more common statistical evaluation techniques than the MSC.

However, the MSC is not dependent on the numerical value of the measurements and places a burden on models with more parameters. MSC is therefore a more objective measurement of the goodness of fit [5]. The analysis of goodness of fit was made for each of the fitting methods and each curve is as presented in Tables 7 and 9.

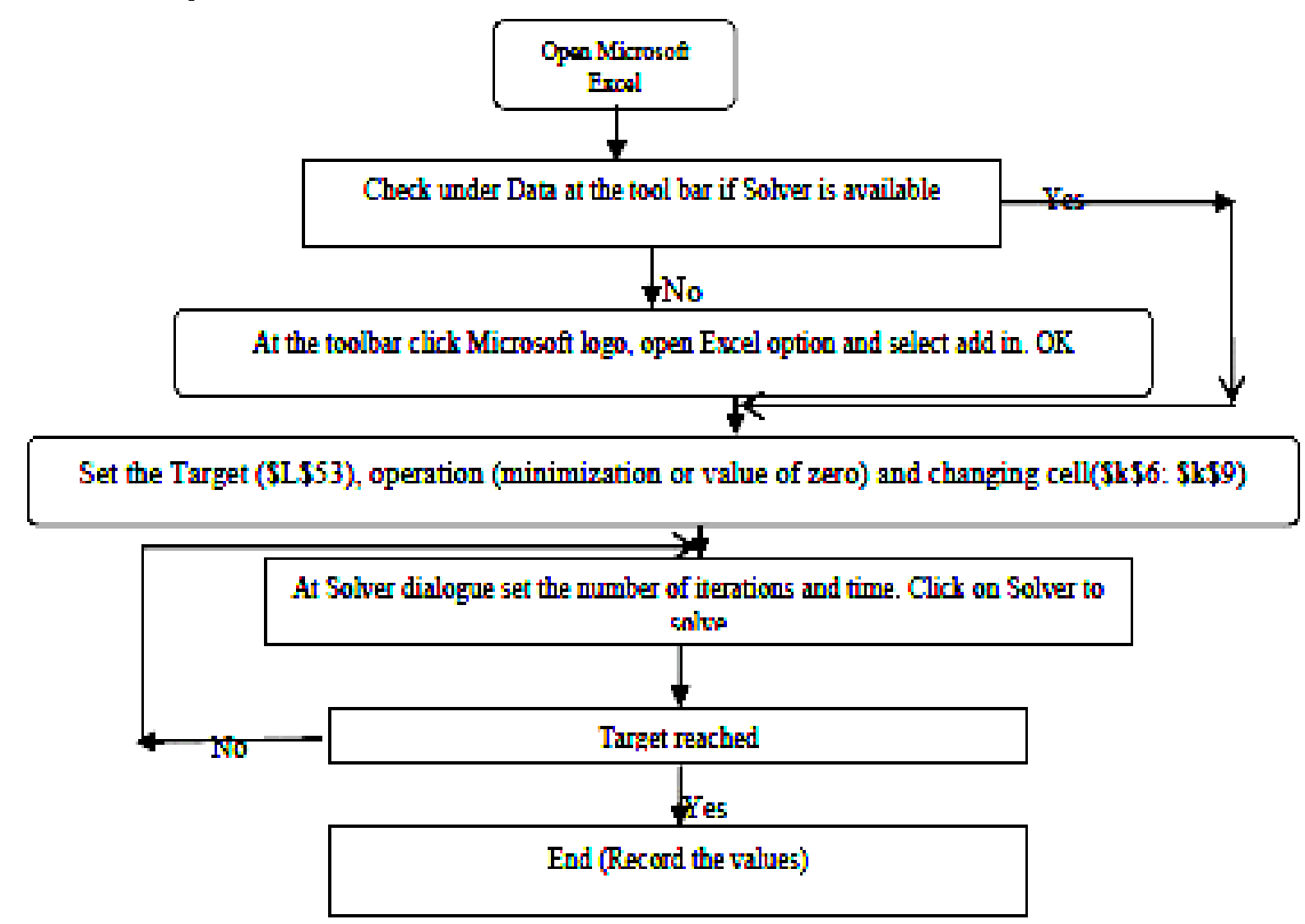

Figure 2: Procedures for using Microsoft Excel Solver in the computation of BOD kinetics

Table 1: The Analysis of Variance of Carbonaceous BOD Concentration

\begin{tabular}{cccccc}
\hline Source of Variation & Sum of Squares & Degree of freedom & Mean Square & F-Value & P. Value \\
\hline Between the samples & 129480 & 5 & 25896 & 2926308 & $4.97 \times 10^{-07}$ \\
Within the BOD Consumed & 2363633 & 4 & 590908.3 & 439.5549 & $3.53 \times 10^{-19}$ \\
Error & 26886.67 & 20 & 1344.333 & & \\
\hline Total & 2520000 & 29 & & \\
\hline
\end{tabular}

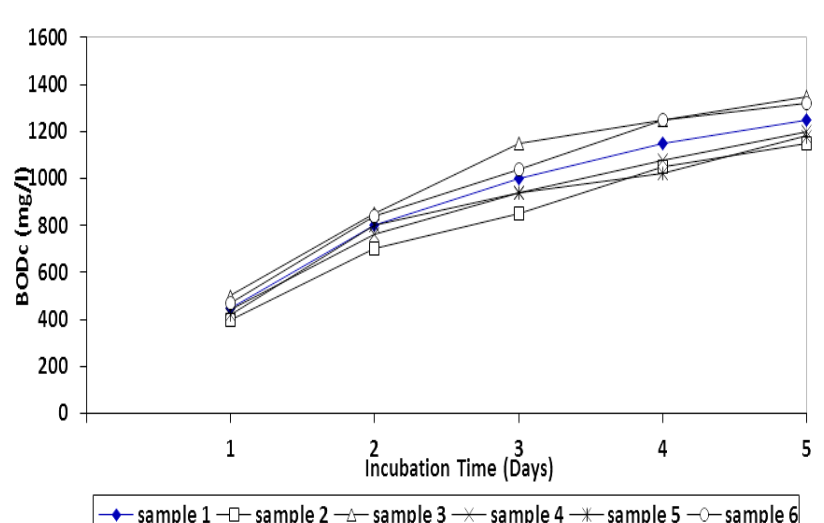

Figure 3: Pattern of $\mathrm{BOD}_{c}$ Removed

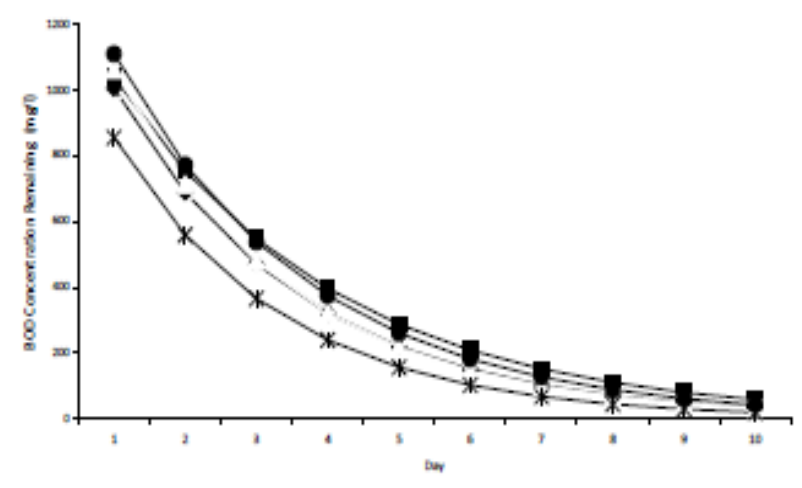

Figure 4: Pattern of BODc remaining 


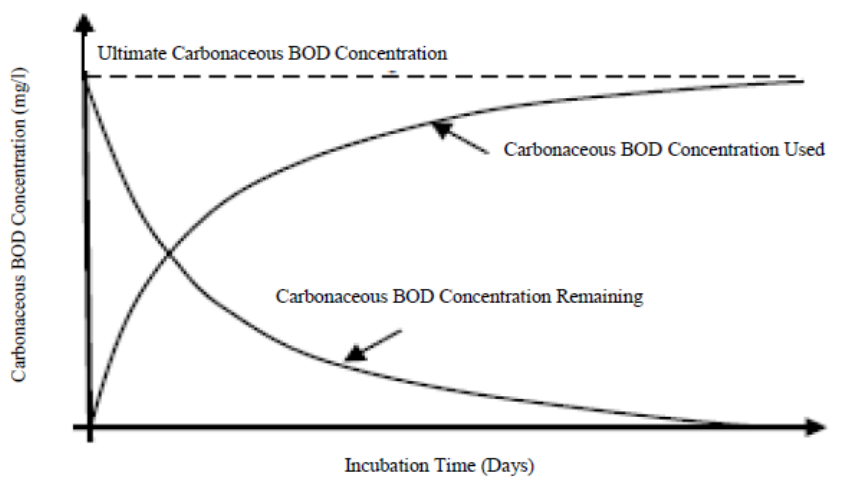

Figure 5: Pattern of Carbonaceous BOD Concentration in First Order Kinetics

From these results (Tables 6 and 8), it is clear that using the Microsoft Excel Solver method results (in all cases) in the smallest relative error (2.02\%), the lowest AIC (43.54) and the highest MSC (4.18). Figures 6 to 8 show the experimental BOD $_{c}$ for the first 5-days runs together with the fitting that resulted. The nonlinear regression method (graph 2) is the next to the Microsoft Excel Solver method. The non-linear regression method (graph 2) can be implemented on any electronic graphical systems, and most plotting packages have it built in too. Its drawback is that it gives a larger relative error (9.91\%), a larger AIC
(56.39) and a lower MSC (1.61) than Microsoft Excel Solver method due to the discrete estimation of the slope which was made at each point (Figure 6). The next method after the non-linear regression method (graph 2) is the graph 1 (non- linear regression). The method can be implemented on electronic devices, and most plotting packages have it built in too (Figure 7).

Its drawback is that it gives a larger relative error (10.57 \%), a larger AIC (56.97) and a lower MSC (1.49) than Microsoft Excel Solver and non- linear regression method graph 2 due to the discrete estimation of the slope which was made at each point.

The next method after the graph 1 method is the least squares method (which is also easy to implement). The method originated from the similarity in shapes of an arbitrary linear function with that of the $\mathrm{BOD}_{\mathrm{c}}$ curve, which is not always true. Its drawback is that it gives a larger relative error (20.45\%), a larger AIC (64.36) and a lower MSC (0.01) than previously mentioned methods due to the discrete estimation of the slope which was made at each point with respect to the incubation period.

Table 2: Values of Ultimate BOD Concentration from all the Methods used

\begin{tabular}{llllllll}
\hline Solution and Method & Sample 1 & Sample 2 & Sample 3 & Sample 4 & Sample 5 & Sample 6 & Average \\
\hline Microsoft Excel Solver & 1538.8 & 1368.7 & 1697.6 & 1388.6 & 1393.07 & 1670.7 & 1509.6 \\
Least Squares & 1780.8 & 1673.8 & 1889.4 & 1725.1 & 1595.64 & 1867.4 & 1755.4 \\
Graphical 1 & 1481.9 & 1445.2 & 1594.8 & 1416.4 & 1404.92 & 1593.8 & 1489.5 \\
Graphical 2 & 1770.0 & 1454.2 & 1991.1 & 1746.8 & 1785.40 & 1794.1 & 1756.9 \\
Graphical 3 & 3510.0 & 3260.4 & 3806.6 & 3298.4 & 3198.13 & 3785.23 & 3476.5 \\
\hline
\end{tabular}

Table 3: Values of Analysis of Variance of Ultimate BOD Concentration from all the Methods used

\begin{tabular}{|c|c|c|c|c|c|}
\hline Source of Variation & Sum of Squares & Degree of freedom & Mean Square & F- Value & P-value \\
\hline Within the Methods Used & 16799739 & 4 & 4199935 & 451.4 & 0.00000 \\
\hline Between Ultimate BOD Concentration & 535129 & 5 & 107025.9 & 11.5 & 0.00002 \\
\hline Error & 186080 & 20 & 9304.025 & & \\
\hline Total & 17520949 & 29 & & & \\
\hline
\end{tabular}

Table 4: Values of BOD Concentration Removal Rate from all the Methods used

\begin{tabular}{llllllll}
\hline Solution and Method & Sample 1 & Sample & Sample 3 & Sample 4 & Sample 5 & \multirow{2}{*}{ Sample 6 } & Average \\
\hline Microsoft Excel Solver & -0.346 & -0.346 & -0.349 & -0.381 & -0.359 & -0.330 & -0.352 \\
Least Squares & -0.386 & -0.318 & -0.447 & -0.343 & -0.349 & -0.437 & -0.380 \\
Graphical 1 & -0.453 & -0.374 & -0.470 & -0.451 & -0.443 & -0.433 & -0.437 \\
Graphical 2 & -0.241 & -0.252 & -0.237 & -0.236 & -0.231 & -0.246 & -0.240 \\
Graphical 3 & -0.151 & -0.139 & -0.154 & -0.155 & -0.160 & -0.145 & -0.151 \\
\hline
\end{tabular}


Table 5: Values of Analysis of Variance of Ultimate BOD Concentration from all the Methods used

\begin{tabular}{lllll}
\hline Source of Variation & $\begin{array}{l}\text { Sum of } \\
\text { Squares }\end{array}$ & $\begin{array}{l}\text { Degree of } \\
\text { freedom }\end{array}$ & $\begin{array}{l}\text { Mean } \\
\text { Square }\end{array}$ & $\begin{array}{l}\text { F-Value } \\
\text { value }\end{array}$ \\
\hline Within the Methods Used & 0.318 & 4 & 0.07959 & 100.118 \\
$\begin{array}{l}\text { Between BOD Concentration Removal } \\
\text { rate }\end{array}$ & 0.006 & 5 & 0.0000 & 3 \\
$\begin{array}{l}\text { Error } \\
\text { Total }\end{array}$ & 0.016 & 20 & 0.000795 & 5 \\
\hline
\end{tabular}

Table 6: Statistical Evaluation (Relative error, MSC and AIC) of all the Methods

\begin{tabular}{|c|c|c|c|c|c|c|c|}
\hline & $\begin{array}{c}\text { Statistical } \\
\text { Evaluation }\end{array}$ & Sample 1 & Sample 2 & Sample 3 & Sample 4 & Sample 5 & Sample 6 \\
\hline \multirow{4}{*}{$\begin{array}{l}\text { Microsoft } \\
\text { Excel Solver }\end{array}$} & Relative Error & 1.22 & 2.16 & 2.10 & 1.05 & 3.75 & 1.83 \\
\hline & Total Error & 260.10 & 522.02 & 1137.27 & 154.91 & 2007.50 & 539.55 \\
\hline & AIC & 39.85 & 43.34 & 47.23 & 37.26 & 50.07 & 43.50 \\
\hline & MSC & 4.94 & 4.11 & 3.63 & 5.32 & 2.70 & 4.36 \\
\hline \multirow{4}{*}{$\begin{array}{c}\text { Least } \\
\text { Squares }\end{array}$} & Relative Error & 22.44 & 15.64 & 27.95 & 16.31 & 10.32 & 30.06 \\
\hline & Total Error & 45073.98 & 20026.24 & 76453.01 & 26120.70 & 12604.48 & 80472.66 \\
\hline & AIC & 65.63 & 61.57 & 68.27 & 62.90 & 59.26 & 68.53 \\
\hline & MSC & -0.22 & 0.46 & -0.58 & 0.20 & 0.86 & -0.64 \\
\hline \multirow{4}{*}{ Graphical 1} & Relative Error & 10.89 & 9.83 & 10.71 & 10.90 & 10.63 & 10.48 \\
\hline & Total Error & 7854.75 & 6425.94 & 9220.18 & 7898.44 & 8509.55 & 8266.26 \\
\hline & $\mathrm{AIC}$ & 56.89 & 55.89 & 57.69 & 56.92 & 57.29 & 57.15 \\
\hline & MSC & 1.53 & 1.60 & 1.54 & 1.39 & 1.25 & 1.63 \\
\hline \multirow{4}{*}{ Graphical 2} & Relative Error & 9.23 & 13.54 & 8.82 & 7.60 & 8.81 & 11.46 \\
\hline & Total Error & 6368.16 & 11104.87 & 7291.19 & 3841.08 & 5895.08 & 11039.53 \\
\hline & $\mathrm{AIC}$ & 55.84 & 58.62 & 56.52 & 53.31 & 55.46 & 58.59 \\
\hline & MSC & 1.74 & 1.05 & 1.77 & 2.11 & 1.62 & 1.35 \\
\hline \multirow{4}{*}{ Graphical 3} & Relative Error & 27.48 & 25.10 & 28.26 & 28.63 & 29.84 & 27.60 \\
\hline & Total Error & 130214.75 & 86770.44 & 165263.11 & 125929.29 & 133204.41 & 129277.79 \\
\hline & AIC & 70.93 & 68.90 & 72.12 & 70.76 & 71.05 & 70.81 \\
\hline & MSC & -1.28 & -1.01 & -1.35 & -1.38 & -1.50 & -1.28 \\
\hline
\end{tabular}

Table 7: ANOVA the Statistical Evaluation (Relative error, MSC and AIC) of all the Methods

\begin{tabular}{llllll}
\hline Source of Variation & Sum of Squares & Degree of freedom & Mean Square & F- Value & P-value \\
\hline Within Statistical Evaluation Method & $1.00 \times 10^{11}$ & 19 & $5.28 \times 10^{9}$ & 73.43 & $3.14 \times 10^{-48}$ \\
Between BOD Kinetics Samples & $6.03 \times 10^{8}$ & 5 & $1.21 \times 10^{8}$ & 1.68 & 0.147667 \\
Error & $6.83 \times 10^{9}$ & 95 & 71941606 & \\
Total & $1.08 \times 10^{11}$ & 119 & & \\
\hline
\end{tabular}

Table 8: Summary of the Statistical Evaluation (Relative error, MSC and AIC) of all the Methods

\begin{tabular}{llllll}
\hline \multirow{2}{*}{ Statistical Evaluation } & $\begin{array}{l}\text { Microsoft Excel } \\
\text { Solver }\end{array}$ & $\begin{array}{l}\text { Least } \\
\text { Squares }\end{array}$ & Graphical 1 & Graphical 2 & Graphical 3 \\
\hline Relative Error & 2.02 & 20.45 & 10.57 & 9.91 & 27.60 \\
Total Error & 770.23 & 43458.51 & 8029.19 & 7589.99 & 129277.79 \\
AIC & 43.54 & 64.36 & 56.97 & 56.39 & 70.81 \\
MSC & 4.18 & 0.01 & 1.49 & 1.61 & -1.28 \\
\hline
\end{tabular}

Table 9: ANOVA of Summary of the Statistical Evaluation of all the Methods

\begin{tabular}{|c|c|c|c|c|c|}
\hline Source of Variation & Sum of Squares & Degree of freedom & Mean Square & F- Value & P-value \\
\hline Within Statistical Evaluation Method & $5.36 \times 10^{9}$ & 3 & $1.79 \times 10^{9}$ & 2.470 & 0.111893 \\
\hline Between BOD Kinetics Methods & $2.89 \times 10^{9}$ & 4 & $7.24 \times 10^{8}$ & 1.001 & 0.444579 \\
\hline Error & $8.68 \times 10^{9}$ & 12 & $7.23 \times 10^{8}$ & & \\
\hline Total & $1.69 \times 10^{10}$ & 19 & & & \\
\hline
\end{tabular}



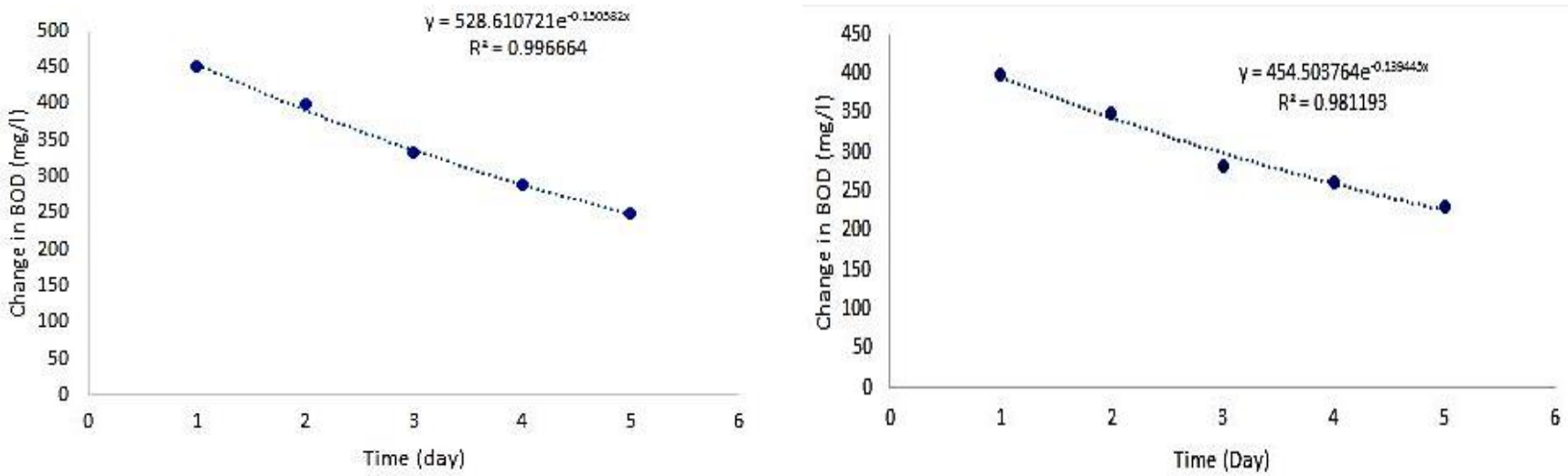

Sample 1
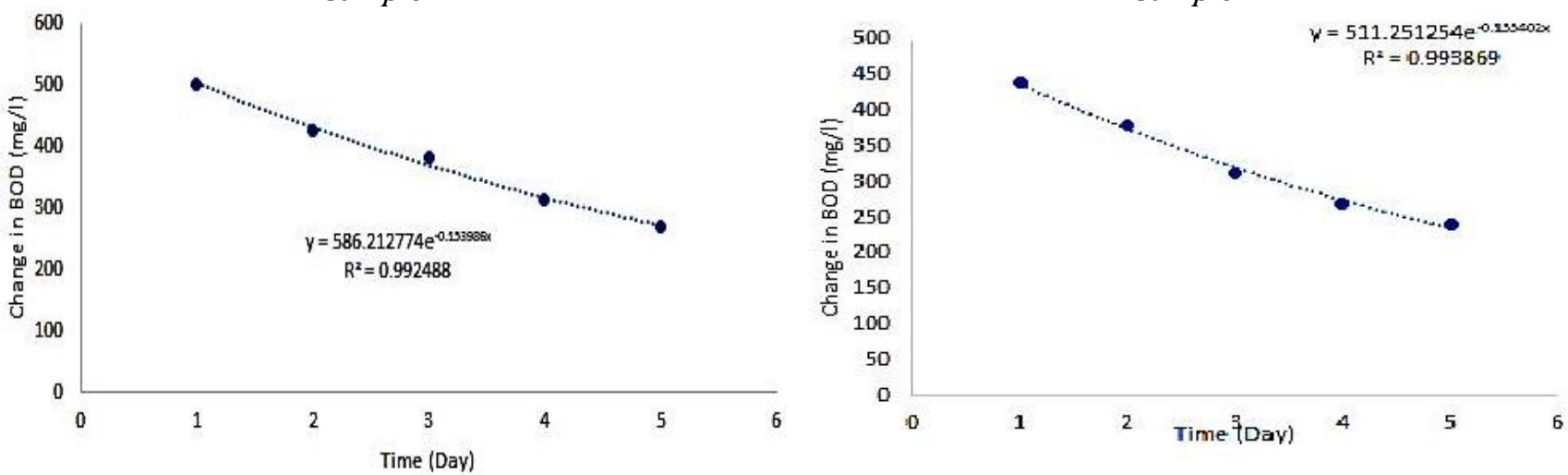

Sample 3
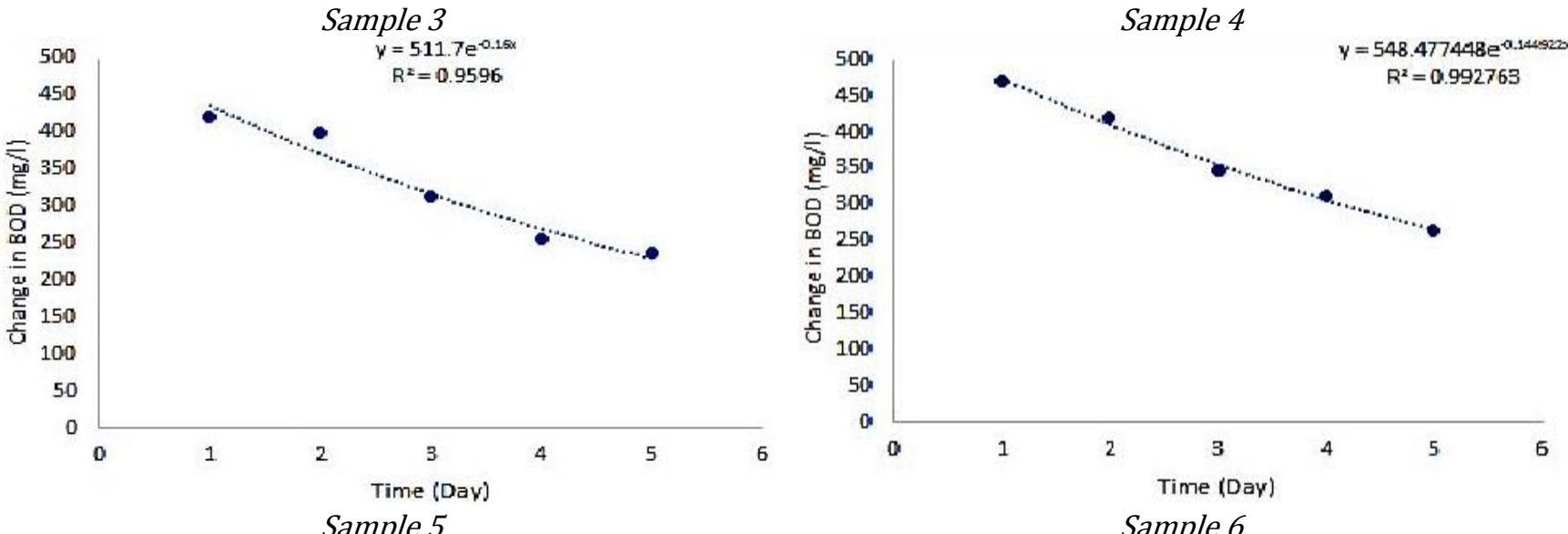

Sample 6

Figure 6: Solution of experimental $B O D_{C}$ using graph 1 of moment method

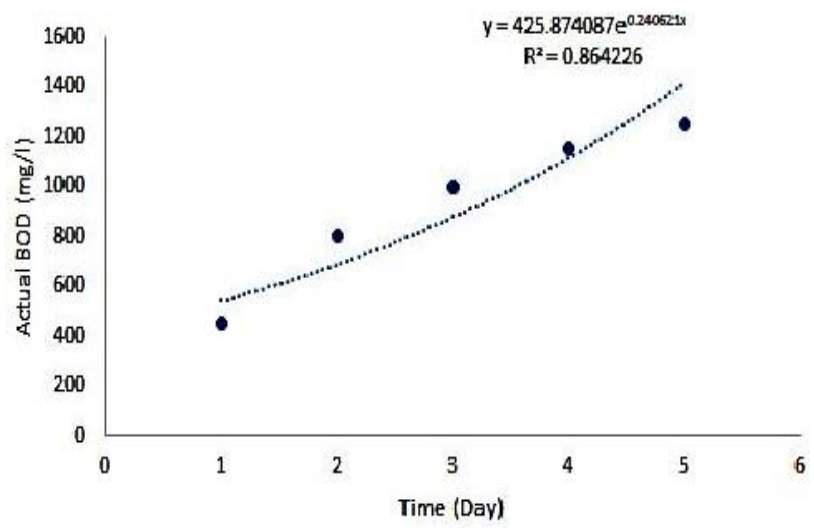

Sample 1

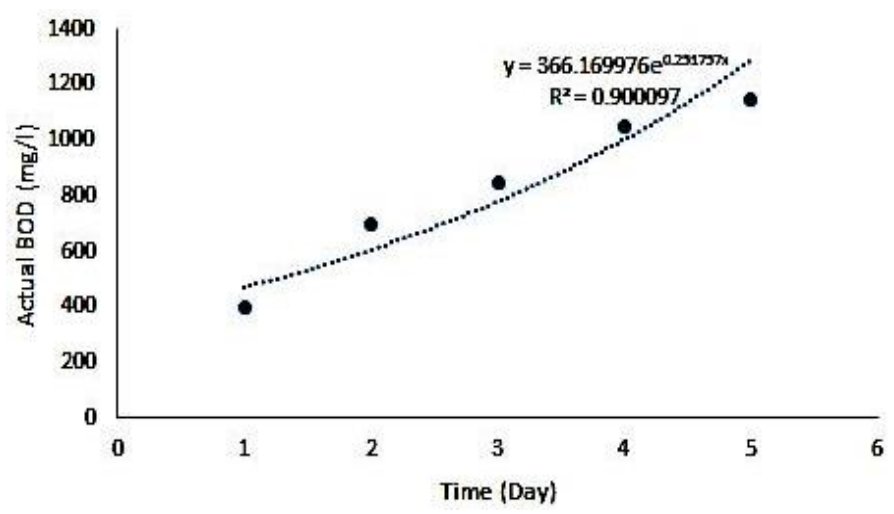

Sample 2 

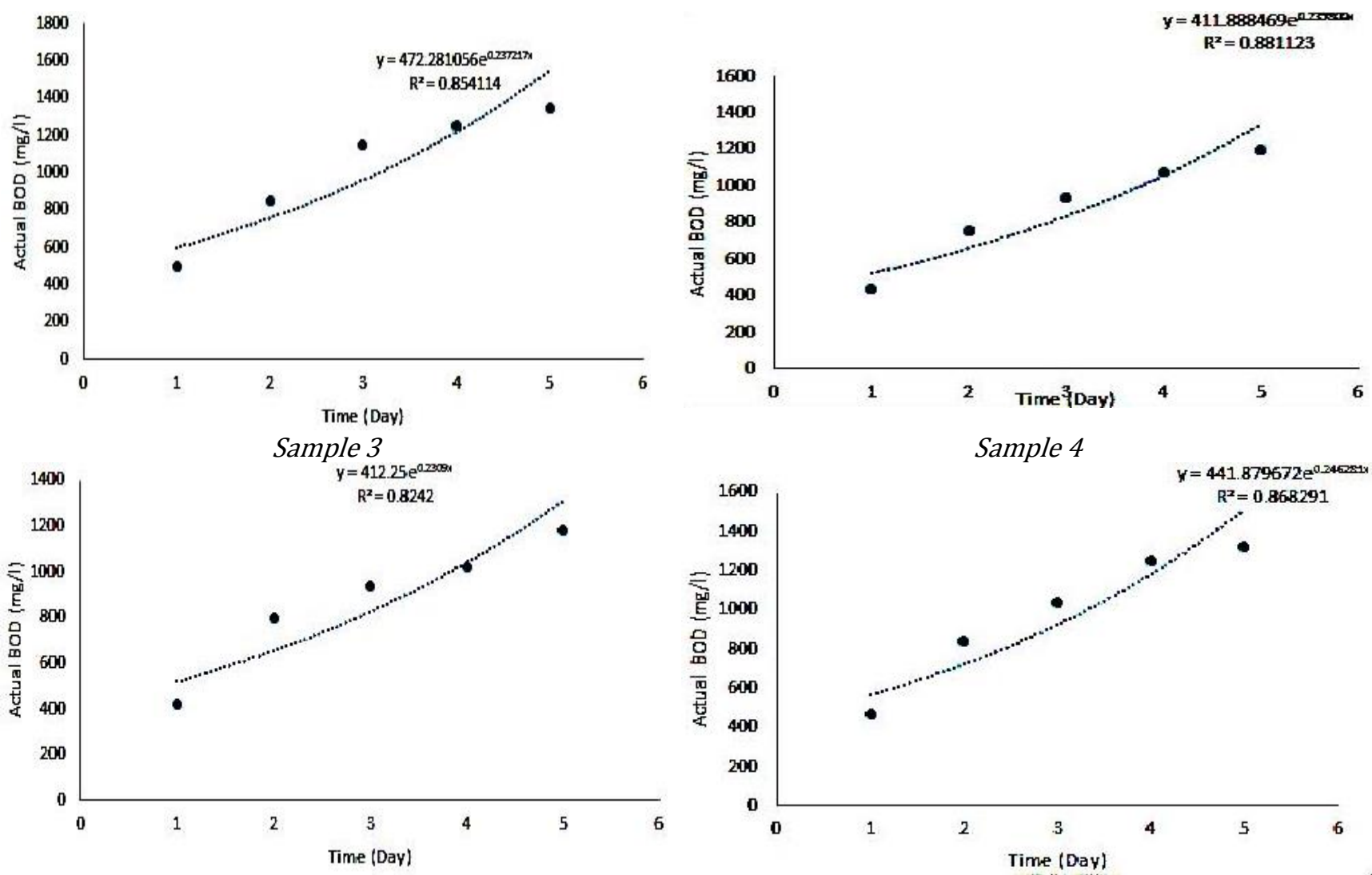

Sample 5

Sample 6

Figure 7: Solution experimental BODC using Graph 2 of Moment method
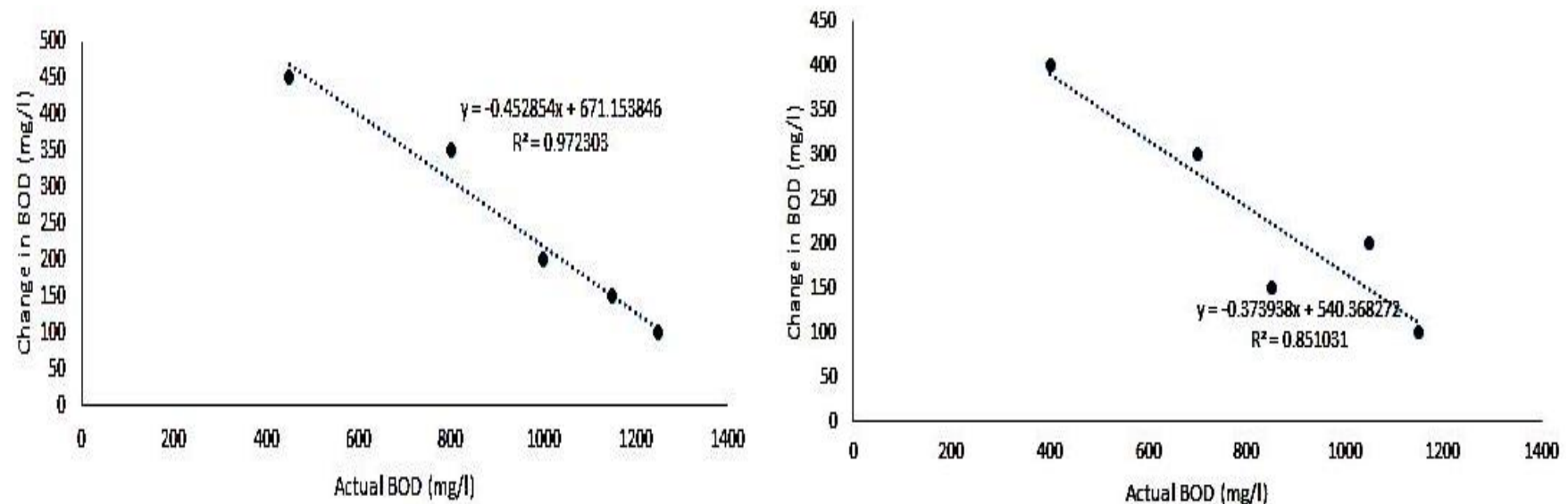

Sample 1
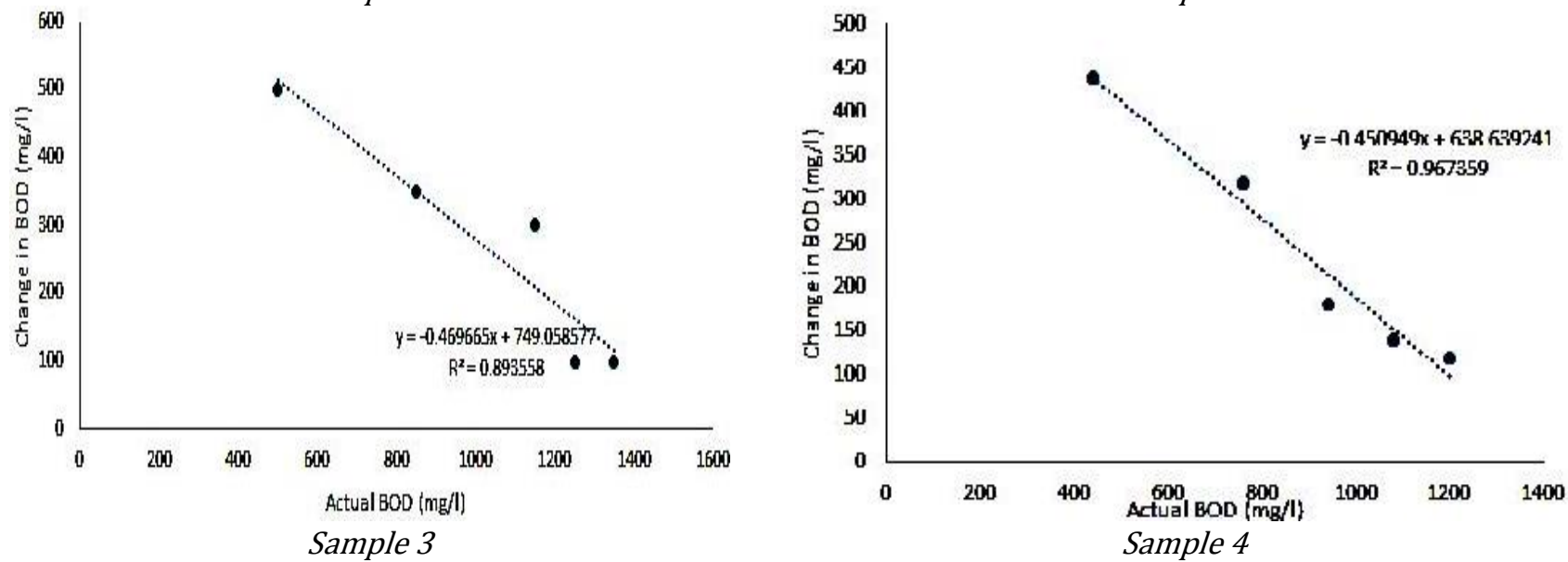


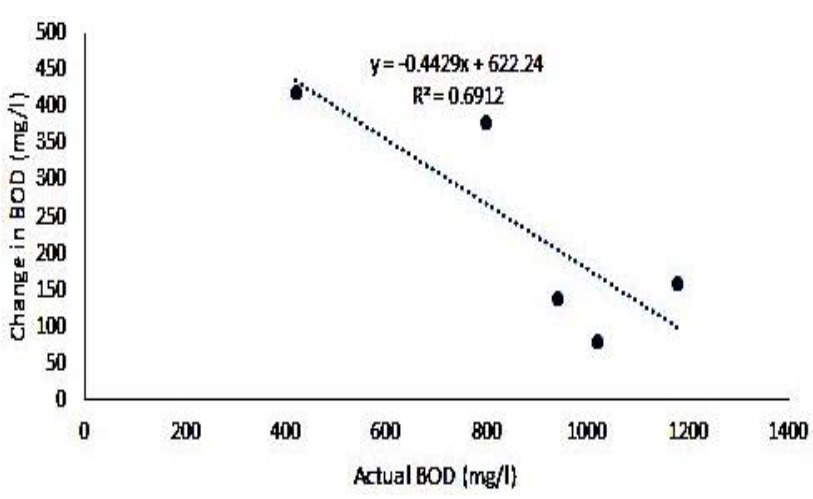

Sample 5

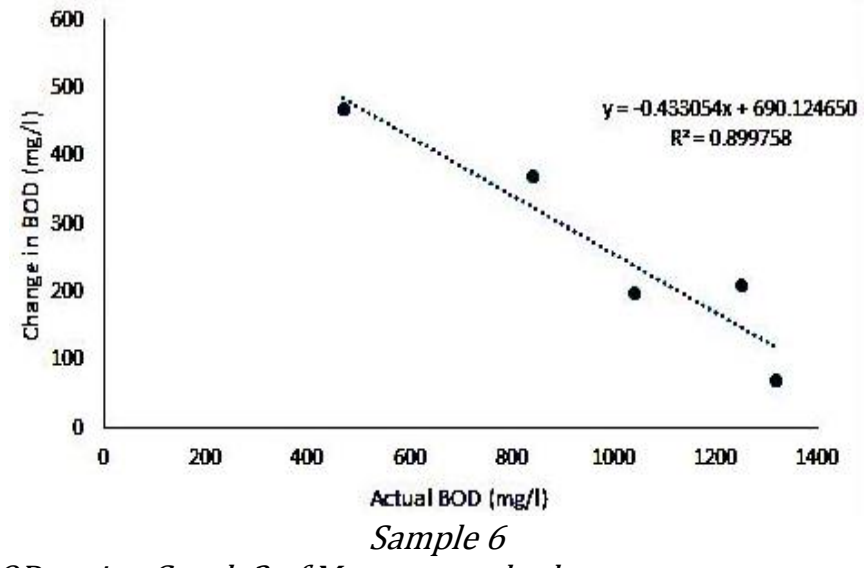

Sample 6

Figure 8: Solution of experimental BODC using Graph 3 of Moment method

. The other method (linear method of Moment method, graph 3) had its relative error greater than other methods (Figure 8). The average relative error was $27.60 \%$; The average of MSC and AIC were -1.28 and 70.81 respectively. These results indicate that accuracies of the method are lower than expected, which makes them not applicable in environmental engineering (error $>5 \%$ ). Although it can be argued that Microsoft Excel Solver and non-linear methods are more difficult to implement, the extended use of computers (high speed with relatively high capacity and high read only memory (ROM)) and the existence of computer packages or routines for non-linear parameter estimation have made its implementation much simpler. Therefore, Microsoft Excel Solve should be the solution of choice in the determination of first order kinetics parameter of $\mathrm{BOD}_{\mathrm{c}}$ in Moment method.

\section{CONCLUSION}

The study utilised Microsoft Excel Solver and other solutions of Moment methods. The solutions were evaluated through selected Biochemical Oxygen Demand (BOD) first order kinetics toward error free kinetics parameters determination. It can be concluded based on the result of the study that:

i. Microsoft Excel Solver is the best solution for estimating first order kinetics parameters of $\mathrm{BOD}_{\mathrm{c}}$;

ii. non-linear regression and least square solutions should be used as an alternative to Microsoft Excel Solver solution for BOD kinetic parameters determination using moment method; and

iii. There is the need to evaluate other BOD kinetics methods and conduct their statistical evaluations.

\section{REFERENCES}

[1] Kim, D.-H; Choi, E; Yun, Z. and Kim, S.-W.. Nitrogen removal from piggery waste with anaerobic pretreatment. Water Science and Technology, Vol. 49 Number 5, pp 165-171, 2004.

[2] Li, Z. and Wrenn, B. A. Effects of ferric hydroxide on the anaerobic biodegradation kinetics and toxicity of vegetable oil in freshwater sediments. Water Research Vol. 38, Number 18, , pp3859. 3868, 2004.

[3] Tadesse, I, Green, F.B. and Puhakka, J.A. Seasonal and diurnal variations of temperature, $\mathrm{pH}$ and dissolved oxygen in advanced integrated wastewater pond system treating tannery effluent. Water Research Vol. 38, Number 3, pp 645-654, 2004.

[4] Ian, G. M. Robert, I. M., and Daniel, T. G A double exponential model for biochemical oxygen demand. Bioresource Technology Vol. 97, pp.273$282,2006$.

[5] Oke, I. A. ; Ismail, A. ; Lukman, S. ; Fogji, P.U ; Adeosun, 0. 0. ; Amele, S.A. and Bolorunduro, A. K. An Improved Solution of First Order Kinetics for Biochemical Oxygen Demand. Ife Journal of Science Vol. 18, Number 3, pp 730- 739, 2016.

[6] Mahmood, T and Paice, M. Aerated Stabilization Basin Design and Operating Practices in the Canadian Pulp and Paper Industry. Journal Environ. Sci. Vol. 5, pp. 383-395, 2006.

[7] Oke, I. A; Otun, J.A and Adie, D.B. An Assessment of Selected Methods in Environmental Pollution Control. Journal of Food, Agriculture and Environment, Vol. 7, Number 1, pp186-191, 2009.

[8] Schroeder, E. D.. Water and Wastewater Treatment. International Student edn, McGraw Hill Inc, Tokyo. 1977.

[9] Tebbutt, T. H. Y. Principles of Water Quality Control, $3^{\text {rd }}$ edn, Pergamon Press, Oxford. 1991.

[10] Metcalf and Eddy Inc. Wastewater Engineering Treatment Disposal and Reuse, $3^{\text {rd }}$ edn, McGrawHill Book Company, New York. 1991. 
[11] Viessman, W. (Jr). and Hammer, M. J. Water Supply and Pollution Control, $5^{\text {th }}$ edn, Harper Collins College Publishers, New York. 1993.

[12] Oke, I. A., "Tertiary Treatment of Textile Wastewater by means of a Carbonaceous filter", Unpublished M.Sc. Thesis, Department of Water Resources and Environmental Engineering, Ahmadu Bello University, Zaria. Nigeria. 2001.

[13] White, J.B.: The design of sewers and sewage Treatment works, $1^{\text {st }}$ edn, Edward Arnold Publisher Ltd, London. 1970

[14] Fasanmi, F. O. Short-term Investigation of a one pond wastewater Stabilization system for Partial Treatment of a Domestic Wastewaters. Ife Journal of Technology, Vol. 4, Number 1, pp 1-4, 1994.

[15] Adrian, D. D. and Sanders, T.G.: Oxygen sag equation for half order BOD kinetics. Journal of Environmental Systems, Vol. 22, Number 4, , pp 341-351, 1993.

[16] Adrian, D.D. and Sanders, T.G. Oxygen sag equation for second-order BOD decay. Water Research, Vol. 32, Number 3, 1998, , pp 840-848.

[17] Fujimoto, Y. Graphical use of first stage BOD equation. Journal of Water Pollution Control Federation, Vol. 36, Number 1, 1964 , pp 69-71.

[18] Borsuk, M.E. and Stow, C.A.: Byesian parameter estimation in a mixed-order of BOD decay. Water Research, Vol. 34, Number 6, pp.1830-1836, 2000.

[19] Hewitt, J. P. and Hunter, J. V.: A comparison of the methods used to calculate first order BOD equation constants. Water Research, Vol. 9, pp 683-687, 1975.

[20] Hewitt, J. P., Hunter, J.V. and Lockwood, D. A multiorder approach to BOD kinetics. Water Research, Vol. 13, pp 325-329, 1979.

[21] Keshavan, K., Weber, W.J., and Carlson, R.H. Discussion to "Second order equation for BOD" by Young J.C. and Clark J.W. Journal of the Sanitary Engineering Division ASCE, Vol. 91, Number SA3, pp. 136-140, 1965.

[22] Liu, J., Olsson, G. and Mattiasson, B. Short-term BOD (BODst) as a parameter for on-line monitoring of biological treatment process. Part I. A novel design of BOD biosensor for easy renewal of bio-receptor. Biosensors and Bioelectronics, Vol. 20, pp 562-570, 2004

[23] Marske, D.M., and Polkowsky, L.B. Evaluation of methods for estimating biochemical oxygen demand parameters. Journal of Water Pollution Control Federation, Vol. 44, Number 10, 1972, pp 1987-2000.

[24] Mason, I. G., Mclachlan, R. I., and Gerard, D. T.: A double exponential model for biochemical oxygen demand. Bioresource Technology, Vol. 97, pp 273282, 2006.

[25] Moore, E.W., Thomas, H.A. and Snow, W. B.: Simplified method for analysis of BOD data. Sewage and Industrial Wastes, Vol. October, pp 1343-1355, 1950.

[26] Navone, R. A new method for calculating K and L for sewage. Water and Sewage Works, Vol. July, pp 285-286, 1960.

[27] Reynolds, D.M. and Ahmad, S.R. Rapid and direct determination of wastewater BOD values using a fluorescence technique. Water Research, Vol. 31, Number 8, 1997, pp 2012-2018.

[28] Sheehy, L.P. Rapid methods for solving first-order equations, Journal of Water Pollution Control Federation, Vol. 32, Number 6, pp 646-652, 1960.

[29] Siwiec, T., Kiedryńska, L. Abramowicz, K., Rewicka, A. and Nowak, P BOD measuring and modelling methods - review. Land Reclamation. Vol. 43, Number 2, pp 143-153, 2011.

[30] Siwiec, T., Kiedryńska, L. Abramowicz, K., and Rewicka, A. Analysis of chosen models describing the changes in $\mathrm{BOD}_{5}$ in sewages. Environment Protection Engineering, Vol. 38, Number 2, pp 61 76, 2012.

[31] Sohn, M. J., Lee, J. W., Chung, C., Ihn, G. S. and Hong, D. Rapid estimation of biochemical oxygen demand using a microbial multi- staged bioreactor. Analytica Chimica Acta, Vol. 313, pp 221-227, 1995.

[32] Swamee, P. K. and Ojha C. S. P. Modelling of BOD exertion curve. Water Research, Vol. 25, Number 7, pp 901-902, 1991.

[33] Thomas, H.A. Graphical determination of BOD curve constants. Water and Sewage Works, Vol. March, pp 123-124, 1950.

[34] Weber, W. J. and Carlson, R.H. Discussion to "Second order equation for BOD" by Young J.C. and Clark J.W. Journal of the Sanitary Engineering Division ASCE, Vol. 91, Number SA3, pp 140-147, 1965.

[35] Young J.C. and Clark J.W. Second order equation for BOD. Journal Sanitary Engineering Division ASCE, Vol. 91, Number SA1, pp 43-57, 1965.

[36] Kalamkar, S. G., Rai, R. K., and Shinde, S. M., Determination of Constants of BOD modelsProceedings of 3rd IRF International Conference, Goa, India, 10th May-2014.

[36] Srinivasa, Rao, G.V.R.; Srinivasa, M. K and Nagendra, B. D. Biokinetics of Removal of BOD and COD from Domestic Sewage Using Fluidized Bed Bio-Reactor. Research Inventy: International 
Journal of Engineering and Science. Vol. 5, Number 5, pp 1-6, 2015.

[37] Oke, I. A; Olarinoye N.O; Olajumoke, A.M and Oladepo, K.T. A Novel Statistical Method For Determining Parameters In BOD Kinetic. Journal of Applied Sciences Research. Vol. 2, Number 8, pp 503-509, 2006.

[38] Gullemo, C.; Liliana, M. Carlos, E. V and Gonzales, J. F A short note on the determination of the kinetics parameters for the BOD test. Water $S A$, Vol. 25, Number 3, pp 377-380, 1999.

[39] APHA, Standard Method for the Examination of Water and Wastewater, $21^{\text {st }}$ edn, America Water
Works Association and Water Pollution Control Federation, Washington DC. 2012.

[40] Akaike, H. An information criterion (AIC), Math. Sci. Vol. 14, , pp 1-5, 1976.

[41] Mara, D. D. Domestic Wastewater Treatment in Developing Countries. First Edition Earthscan, London. 2003.

[42] Thomann V. R and Mueller A. J, Principals of Surface Water Quality Modeling, Harper International Edition, Harper and Row, New York. 1887, 